\title{
ALEXANDER MONRO SEGUNDUS AND THE INTERVENTRICULAR FORAMEN
}

\author{
by \\ J. A. SHARP
}

IT is almost impossible to find a text-book in which the name of Alexander Monro Secundus $(1733-1817)$ is not associated with the interventricular foramen, in the generally accepted belief that Monro was responsible for the first and (or) the most accurate account of this foramen. References in publications concerned with the history of eponymous nomenclature encourage this belief. Thus Morton (1954) states that

Monro discovered the communication between the lateral ventricles of the human brain with each other and with the third ventricle, the 'foramen of Monro'.

Similarly Dobson (1946) quotes a passage from Monro Tertius attributing the description of the foramen to his father, Monro Secundus, and herself notes that 'it was first demonstrated in 1753 '.

Going back a little further, Comrie (1927) has the following passage:

Monro's 'Observation on the Structure and Functions of the Nervous System' ( 1783 ) not only summarised and illustrated by admirable plates the current knowledge of the time, but contained numerous additions from his own observation. Among the new points described may be mentioned the foramen connecting the lateral and third ventricles, which has made his name familiar to every medical student.

It may be noted in passing that an American author, Mettler (1947), even ascribes the foramen to Monro Primus (1697-1 767 ).

Most authorities are quite dogmatic in stating that Monro Secundus discovered the interventricular foramen. To throw doubt on this it is only necessary to consult Monro's own publications on the subject, where he stated that other anatomists had been aware of this communication. In the earliest account of his which is available (Monro I 783) he said, apropos the cerebral ventricles:

These cavities have been described by Galen, and by many succeeding Authors of eminence, as all communicating with each other.

At the outset, then, Monro was perfectly honest in pointing out that the presence of a communication between the ventricles was well known, but he goes on to suggest that this communication had not been illustrated before, that its situation was in doubt, and that some workers had entirely overlooked, or denied, its existence. The general impression gained from this portion of Monro's work is that no description of the communication prior to his own was of any value. 


\section{A. Sharp}

To what extent was Monro's work on the interventricular foramen anticipated by the older anatomists? Taking a selection of these in chronological order, we may first refer to the anatomical drawings of Leonardo da Vinci (O'Malley and Saunders 1952), one of which, attributable to the first decade of the sixteenth century, is based on a wax cast of the ventricles of the brain of an ox (fig. I), and clearly shows a communication between each lateral ventricle and the third ventricle. In their notes on this drawing O'Malley and Saunders also fall into the error of ascribing the foramen to Monro Primus.

The ideas of Vesalius on this subject are readily available in translations. Singer (1952) provides the relevant passages from the 'Fabrica'.

Thus the lower part of (each anterior) ventricle is rendered uneven by a certain recess (sinus) extending from the outer side of the ventricle anteriorly and obliquely into the third ventricle (=groove of stria habenularia).

\section{A little later in the same work:}

A common cavity of the ventricles is formed by descent and concurrence of the lower parts of the lateral ventricles below that body (=fornix) which professors of dissection have likened to a tortoise.

Vesalius further mentions the interventricular foramen in his 'Epitome' (Lind 1949):

The lower regions of the ventricles ... are not partitioned from each other by the septum but come together in a common sinus (the third ventricle) lying under the body formed like an arch (fornix); this space extends directly downward as a prominent channel through the substance of the brain into a funnel or basin formed by a thin membrane of that shape (the infundibular recess).

Spigelius (1627) offers no advance on the earlier writings of Vesalius:

Nature in her wisdom has formed two ventricles (for in reality there are only two). From which through the anterior passage of the so-called third ventricle then through the pelvis (it) transmits gradually to the pituitary gland.

Willis (I682) tells much the same story, although less concisely:

Into this (third) ventricle there are two openings, one of which stands in the beginning of it and the other at its end; and through the middle of its extent a downward sloping aperture stretches toward the infundibulum, so that a serous humour coming up to one or other of the foramina flows down immediately to the infundibulum. Furthermore into the same aperture of the infundibulum there is another crossway through the first foramen which is attached near the roots of the fornix; its way is open so that from every quarter of the brain serous humours are carried into this sewer.

Winslow (1732) is more explicit:

The infundibulum opens above immediately before the optic thalami, by the oval hole named Foramen Commune Anterius, and consequently communicates with the lateral ventricles. 


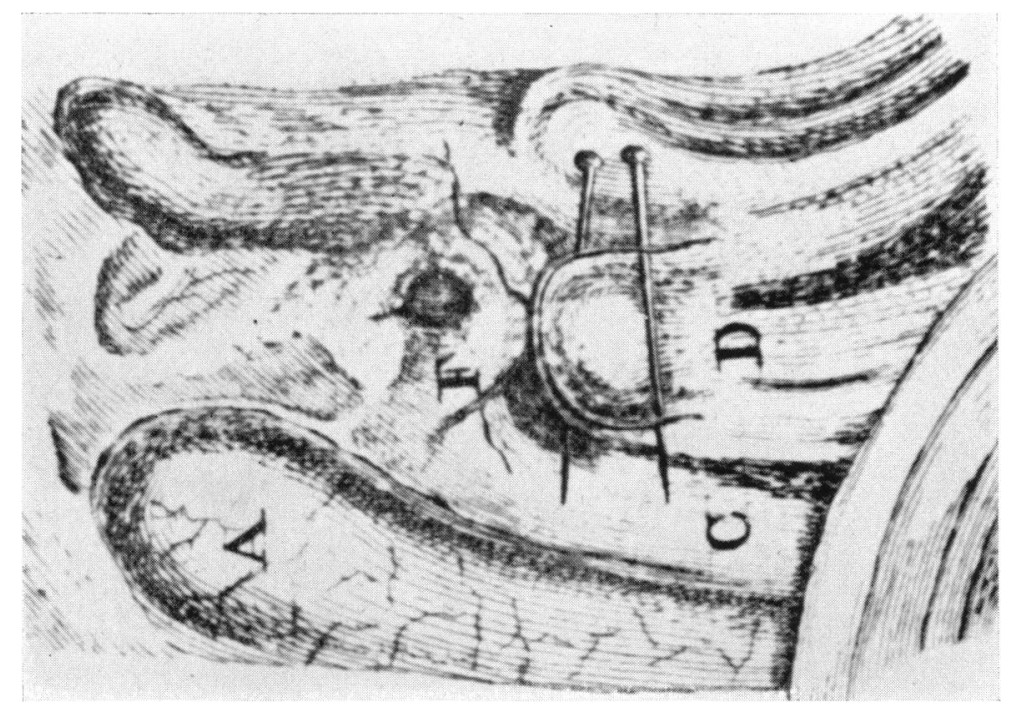

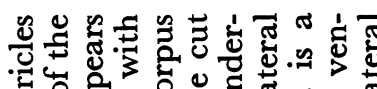
苵

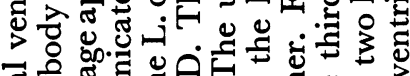

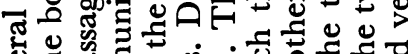

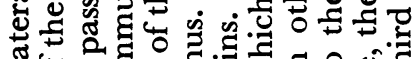

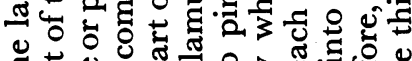

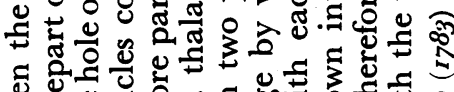

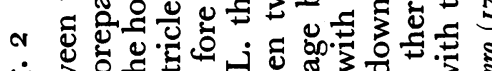

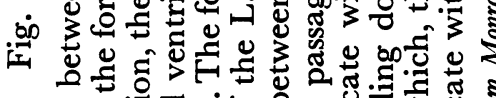

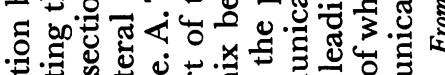

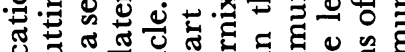
.

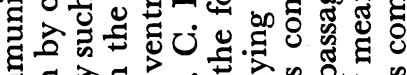

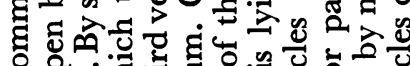
o

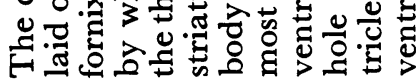

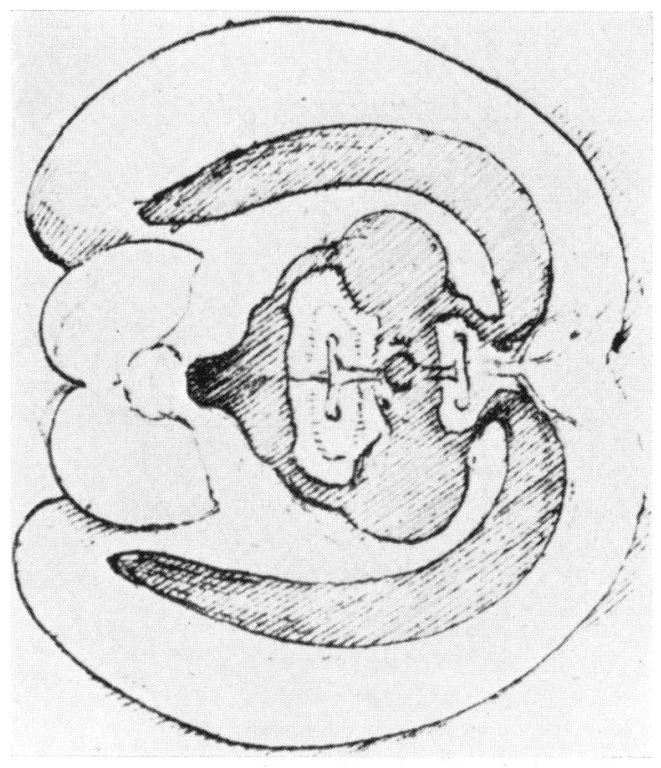

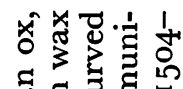
สี पे

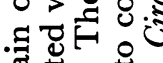
قُّ : 造造造 क.

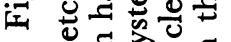

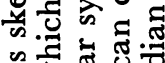
की

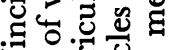
$>$.

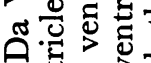
出

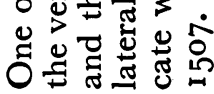




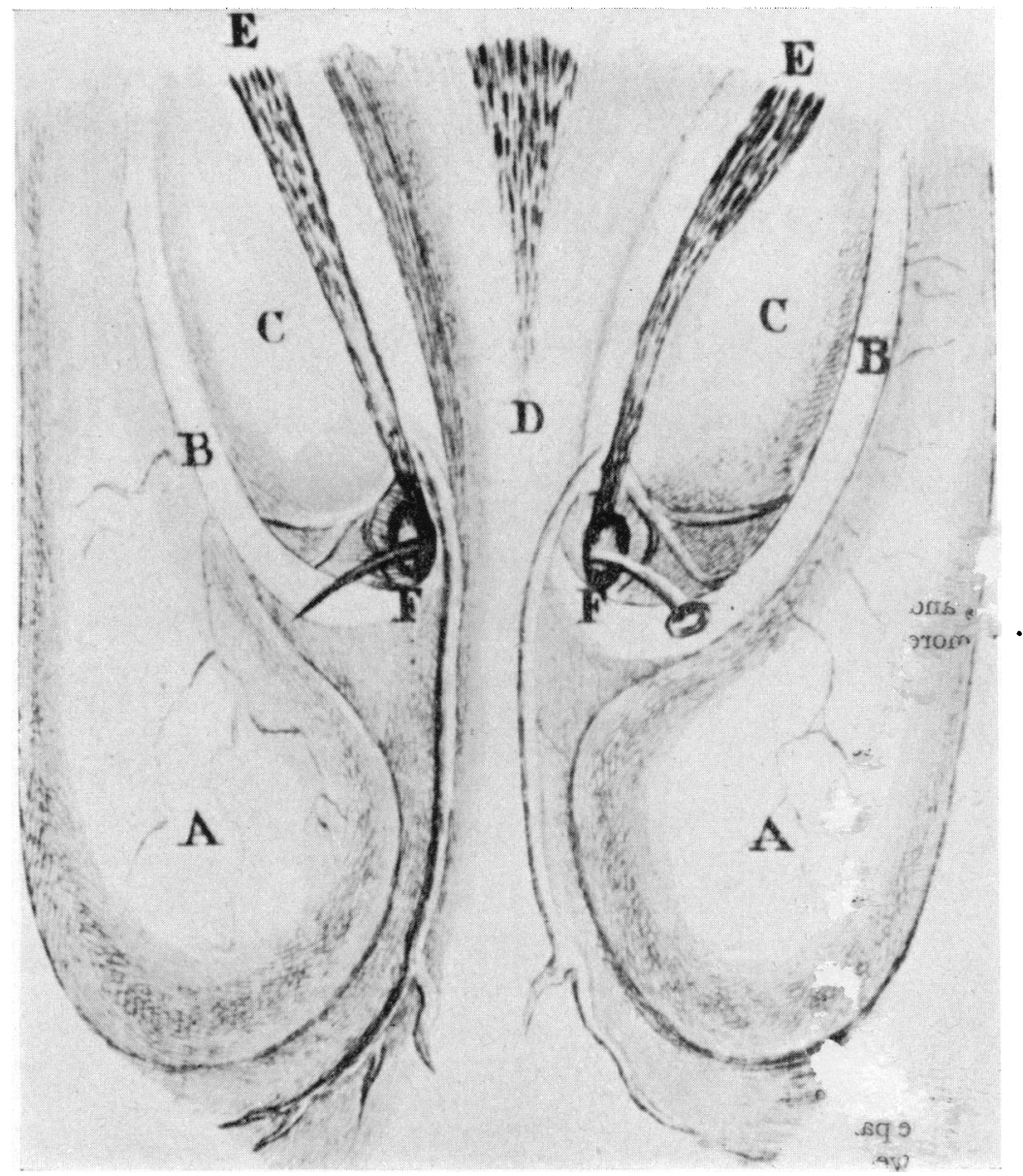

Fig. 3

AA The forepart of the corpus striatum. BB The centrum circulare geminum ('Centrum circulare geminum'=stria terminalis). CG The thalami. D The body of the fornix. EE The choroid plexuses. FF A crooked pin passed through the passage by which the lateral ventricles communicate with each other.

From Monro $(1783)$ 


\section{Alexander Monro Secundus and the Interventricular Foramen}

A little later in the same work Winslow again mentions that the third and lateral ventricles communicate with each other. Haller ( 1776$)$ has the following passage:

The left ventricle is said to open into the right where the two choroid plexuses meet, between the optic thalami, the fornix and the choroid plexus, so that it has long been said that there is one and only one ventricle. I have often gone over that passage with my breath.

The succeeding passages are ambiguous and it is not clear what in fact were Haller's views on this matter.

These representative quotations will serve to emphasize that the communication between third and lateral ventricles was known to, and was described or implied by, a number of anatomists before the time of Monro Secundus. Indeed, this knowledge was not confined to anatomists, since the following extract from Burton's Anatomy of Melancholy would suggest that it formed part of the information available to all educated men of his day:

Of these verebral) ventricles there be three, right, left, and middle. The right and left answer to their site - $d$ beget animal spirits; if they be any way hurt, sense and motion ceaseth. These ventricles, $\mathbf{n}$ over, are held to be the seat of the common sense. The middle ventricle is a common concourse and cavity of them both ... (Burton 1621 ).

To turn now to Monro's own contributions, here is the relevant portion of his first published description (Monro I 783):

After laying open one of the lateral ventricles of the brain in the usual way, leaving the septum between the ventrici s entire, let the gutter which is between the corpora striata and thalami nervorum opticorum, the bottom of which is occupied by the substance called centrum semicirculare geminum, be traced inwards, and it will be found to lead to the forepart of an oval hole, large enough $t w$ admit a goose quill, under the forepart of the fornix. From this hole, a probe can readily he passed into the other lateral ventricle, shewing, in the first place, that the two lateral ventr: ommunicate with each other. When the fornix is next divided transversely, we find this passage has the anteridr crura of the fornix at its fore part, and the joining or midal $r t$ of the choroid plexuses of the lateral ventricles at its back part, and that its middle part is \& ur a passage downwards, named the iter ad infundibulum, or vulva, which should rather be called iter ad tertium ventriculum.

When we afterwards carefully raise, and turn backwards the body of the fornix, we find that the choroid plexuses of the lateral ventricles are connected together by a broad vascular membrane, which adheres closely to the fornix above it, and to the thalami nervorum opticorum below it. Hence, too, this membrane covers and shuts the hole called Anus, and prevents the lateral ventricles from communicating with each other, at any place but that before described.

A careful reading of this extract throws an interesting light on Monro's conception of the mode of communication of the third with the lateral ventricles; it is apparent that he believed the interventricular foramina to lie one at each end of a transversely directed tunnel or passage, constituting a direct connection between the two lateral ventricles, and which, in turn, opens inferiorly into the third ventricle via a vertically disposed aperture which Monro called 'iter ad tertium ventriculum'. This interpretation of the relationship between the 


\section{A. Sharp}

ventricles is illustrated in two of Monro's drawings (figs. 2, 3) from the same publication. In Fig. 3 he marks with a letter F' $a$ natural passage by which the lateral ventricles communicate with each other and with the third ventricle'. In Fig. 2, $\mathrm{F}$ indicates ' $\mathrm{a}$ hole or passage leading down into the third ventricle'. In other words, the two lateral ventricles, according to Monro, share a common orifice into the third ventricle.

It would appear that this first account was not received with general acclaim. At all events, he thought it necessary to reiterate his beliefs in his Treatise on the Brain (Monro I 797). Here he refers to his account of 1783 , and then says:

To my very great surprise, however, I have been informed, that several Teachers of Anatomy in London have told their Pupils, that they had looked for such passages in vain; and therefore ventured to deny their existence.

So determined was Monro to vindicate himself that he went to the length of appending a 'Declaration by the Professors of the Faculty of Physic in the University of Edinburgh', which ends:

We therefore entertain no doubt of the existence of the communication of the Lateral Ventricles of the Brain with each other, and with the Third Ventricle, described by Dr. Monro in the work he published on the Nervous System in 1783 .

Monro's actual description of the region in question is more concise in this second publication than in the earlier one:

An oval hole, situated under the anterior part of the body of the fornix; behind the anterior crura of the fornix and commissura anterior cerebri; on the forepart of the joining of the choroid plexuses of the two lateral ventricles of the brain; and over the fore part of the third ventricle. Hence, at this place, the lateral ventricles of the brain communicate with each other and with the third ventricle.

Obviously, the passage of fourteen years had not altered Monro's views. Although he appears to have encountered opposition to his statements, no published denials of continuity between the ventricles, dating from this period, have been found. It would seem unlikely that any reputable anatomist of the time would fail to confirm the existence of the communication, and it may be that the 'passages' which they had sought in vain were the particular ones described by Monro, and that the 'Teachers of Anatomy in London' were fully aware of the continuity between the third and lateral ventricles, but simply did not agree with Monro's interpretation of them. Such differences in interpretation could well be the result of differing methods of dissecting the brain.

One example of hostile criticism of Monro is available. This was more in the nature of a personal attack on him for presuming to describe something which was already well known, than an attempt to show that his description was false. It is to be found as an appendix to a series of engravings of the brain, the work of Sir Charles Bell (1802). The following extracts illustrate the tenor of this appraisal of Monro: 


\section{Alexander Monro Secundus and the Interventricular Foramen}

The existence of this communication of the Ventricles with each other, has been known since the Anatomy of the Brain became an object of attention; yet it has unaccountably happened that pretensions have been made in the present day to the merit of having discovered this communication, as if a total ignorance had spread over the anatomical world of all that our predecessors had observed or written on this subject. The Anatomists both of ancient and modern times have equally been represented as ignorant of the communication between the Ventricles, as if their writings were not in existence to prove the extent of their knowledge.

Dr. Monro has assumed the merit of discovering the communications betwixt the Ventricles of the Brain ... It is to be regretted, however, that Dr. Monro has been more anxious to bring together the authorities of writers whose accounts are imperfect, and from whose descriptions the ignorance of the older Anatomists respecting these communications might be inferred, than solicitous to support his opinion and observations by respectable authorities.

Bell then examines Monro's references to the older anatomists and attempts to show that Monro, by taking passages from previous accounts out of their context, had given a false idea of the extent and accuracy of the knowledge of this matter. One example may be given from this part of Bell's attack:

A few, says Dr. Monro, have mentioned a place under the Fornix, to which they have given the name of Anus, where they suppose the lateral ventricles to communicate with each other, and at the same time with the third; and he quotes on his margin Vieussens and Winslow. This is by no means accurate; Vieussens says, under the marginal title 'quid Vulva? Vulva nihil aliud est, quam foramen circa anticam ventriculorum anteriorum cerebri regionem, subtus fornicem reconditum, et juxta radices illius excavatum; cujus interventu predicti anteriores ventriculi cum tertio communicant'. The Anus and the Vulva it must be recollected are very distinct parts, and it does not take away from the accuracy of this description, that Vieussens conceived the Anus likewise to form a communication betwixt the Ventricles. It is only the latter of those passages which Dr. Munro has taken notice of, though the quotation I have given immediately precedes.

After further comments in the same vein, Bell goes on to point out that 'there is scarcely a book which we can consult without finding the circumstance of the universal communication betwixt the Ventricles particularly mentioned'. He supports this contention by citing Vesalius and Willis, amongst others.

After reading this attack in full, one cannot help feeling that it is justified, and that Monro Secundus was a little over eager in promulgating his own observations, at the expense of a good deal of quite accurate work which had been published long before his time. One also senses a certain bitterness on the part of Bell. He, too, learned his anatomy in Edinburgh, and we may speculate on the possibility that he coveted the Ghair of Anatomy there, and resented his 'exile' in London.

All the evidence presented so far leads to the conclusion that Monro had no claim whatever to precedence in pointing out the definite existence of a communication between the third and lateral ventricles. It may still be contended, however, that his name ought to be linked with the interventricular foramen, on the grounds that his description was the first accurate one. But this will not withstand examination; we have seen that Monro supposed that the two lateral ventricles open directly into each other via a transverse tunnel or passage running above the anterior part of the third ventricle, which in turn opens into this transverse passage via a vertical mid-line channel. 


\section{A. Sharp}

The true relationship between the ventricles is most accurately envisaged by means of casts of their cavities. This method was employed by Retzius (1900) and has most recently been used by Last and Tompsett (1952), who have produced excellent casts by means of the plastic injection technique. Their description, based on these casts, is as follows:

The lateral ventricle is connected to the third ventricle by a short thick stalk of resin, representing the interventricular foramen. The stalks of the two sides are symmetrical, diverging slightly upwards from the side walls of the third ventricle just behind the notch made by the anterior commissure. The two stalks are joined, separately from each other, to the right and left walls of the body of the third ventricle, the roof of which projects upwards as a sharp ridge between them.

\section{A footnote is appended:}

In other words, the two interventricular foramina do not join each other to make a transverse canal, and in describing them as doing so Monro ( 1783 ) was mistaken; it is possible to pass from one interventricular foramen to the other only by crossing the cavity of the third ventricle. For a century and a half the name 'foramen of Monro' has designated the passage, nowadays called 'interventricular foramen', leading from the lateral into the third ventricle, but Monro in fact described a third foramen leading from the supposed junction of the interventricular foramina into the roof of the third ventricle just behind the anterior pillars of the fornix. Fourteen years later Monro (1 797) still adhered to his original description, though it should be pointed out that he was then far more concerned with proving the existence of a communication between the lateral ventricles and the third ventricle than with the actual form of the communicating foramen.

The present writer feels strongly that there is no justification for the retention of the eponymous term 'foramen of Monro' as a synonym for the interventricular foramen of modern terminology for two reasons; firstly, because Monro added nothing of value to the pre-existing descriptions of the foramen, and secondly because he actually misinterpreted the nature of the communication between the third and lateral ventricles.

\section{REFERENCES}

BELL, C. (1802). The Anatomy of the Brain. London.

Burton, R. (1621). The Anatomy of Melancholy. Oxford.

CoMrie, J. D. (1927). History of Scottish Medicine to 1860. London.

DoBson, J. (1946). Anatomical Eponyms. London.

Hal l e R, A. ( 776 ). Elementa Physiologiae Corporis Humani, rv. Naples.

LAst, R. J. and Tompset, D. H. (1952). 'Casts of the cerebral ventricles'. Brit. F. Surg., $\mathrm{XI}$, 525-43.

LIND, L. R. (1949). The Epitome of Andreas Vesalius. New York.

Metrler, C. C. (1947). History of Medicine. Ed. F. A. Mettler, Philadelphia.

Mon ro, A. (Secundus). (1783). Observations on the Structure and Functions of the Nervous System. Edinburgh.

Monro, A. (Secundus). (1797). Treatise on the Brain, the Eye and the Ear. Edinburgh.

Morton, L. T. (1954). Garrison and Morton's Medical Bibliography. 2nd ed., London. 


\section{Alexander Monro Secundus and the Interventricular Foramen}

O' Malley, C. D. and SAunders, J. B. De G. M. (1952). Leonardo da Vinci on the Human Body. New York.

Retzius, G. (1900). 'Die Gestalt der Hirnventrikel des Menschen nach Metallausgussen dargstellt. Biol. Untersuch., IX, 45.

SINGE R, G. (1952). Vesalius on the Human Brain. London.

S pige lius, A. (1627). De Humani Corporis Fabrica. Venice.

Willis, T. (1682). Opera Omnia. Amsterdam.

Winslow, J. B. (1732). Exposition Anatomique. Paris. 